\title{
Does academic self-concept drive academic achievement?
}

\author{
Kirstine Hansen and Morag Henderson
}

\section{Department of Social Science, University College London.}

\begin{abstract}
Gaps in GCSE attainment have long been the concern of policy makers, academics and social commentators, largely due to the importance of these exams for setting children on their future academic and career pathways. In the past a wide range of factors relating to the pupils, their families and their schools have been found to account for differences in GCSE attainment. In this paper we examine the role of pupils' belief in their own academic ability (academic self-concept). Using Next Steps data, we examine whether pupils with higher academic self-concept do better or worse in their GCSEs than pupils with lower academic self-concept. Results show that on average, controlling for other characteristics, having high academic self-concept increases GCSE scores by 4 grades. When we compare academic self-concept to measured achievement we find that both high and low attainers have higher probabilities of achieving five $A^{*}$-C GCSEs and higher GCSE point scores on average if they have high academic self-concept than similarly able students who have lower academic self-concept.
\end{abstract}

Key words: Academic self-concept, GCSE attainment. 


\section{Introduction}

Self-esteem, having confidence in one's own worth or abilities, and self-concept, an individual's belief about him or herself are held to be related to some of the key social issues of our time (Marsh and Craven 2006). Low self-esteem, it has been argued, is associated with a variety of negative outcomes from mental health problems, substance abuse, through to violent crime and even suicide (Branden, 1994). High self-esteem or self-concept on the other hand is argued to facilitate a variety of positive outcomes and play a role in promoting the realisation of individual potential (Marsh and Craven, 1997, 2006; Craven et al., 2003). In this paper we examine whether a specific aspect of self-concept, academic self-concept (pupils' beliefs in their own academic ability), is associated with academic outcomes. Using data from Next Steps we examine the role academic self-concept plays in understanding differences in GCSE results. More specifically we ask: controlling for other factors, is having a greater belief in your own academic ability associated with an improvement in the grades you achieve at age 16 ? If it does, targeting academic self-concept may offer policy makers interested in reducing attainment gaps an opportunity for intervention that may be less burdensome than influencing the structural factors that contribute to achievement gaps such as parental income or education.

If pupils were accurate at judging their own abilities their academic self-concept would completely reflect their ability and achievement. However, evidence indicates that pupils, are not necessarily good at predicting their own academic ability (see Dunning et al., 2004). In general, pupils tend to overestimate their ability (Falchikov and Boud, 1989), both in actual terms and relative to their peers. However, it varies widely across pupils depending on their characteristics, family backgrounds and the schools they go to. For example, females have been shown to underestimate their academic ability, while males tend to overestimate their abilities and are especially likely to rate their abilities more highly in subjects traditionally thought of as masculine such as mathematics and science (Joffe and Foxman, 1988; Marsh, 1989, Marsh and Yeung, 1998; Sullivan, 2009). Furthermore, children from 
the lower social classes and those with less educated parents tend to have less belief in their academic abilities than their more privileged counterparts (Correll, 2001; Sullivan, 2006). Clearly a student's frame of reference is important for these processes, such that students with high attaining peers will be more likely to consider themselves below average than students of the same ability but surrounded by lower attaining peers. This is known as the Big-Fish-Little-Pond Effect (Marsh and Hau, 2003). Sullivan (2009), using NCDS data found evidence that empirically supported this theory by showing that students at academically selective schools and independent schools had lower academic selfconcept than students in comprehensives.

If, controlling for other characteristics, pupils with higher (or lower) academic self-concept do better (or worse) in any test directly due to their self-concept then understanding these relationships is crucial. Yet the empirical evidence on the relationship between academic self-concept and educational outcomes is mixed. Global measures, such as those used by Baumeister et al. (2003) tend to find no association between self-esteem and academic outcomes but Marsh and Craven (2006) show that global measures of self-esteem and other non-academic components of self-concept fail to pick up the significant associations between a much more specific measure, focusing on academic selfconcept and academic outcomes. In more recent reviews Gorard and others (Gorard, 2012; Gorard at al., 2012; See and Gorard, 2015) argue that the strongest associations are found in studies which fail to measure background factors or prior attainment. Once these variables are controlled for relationships between academic self-concept and cognitive outcomes tends to disappear.

However, Marsh and Craven (2006) highlight a number of papers that show evidence of positive effects of academic self-concept on subsequent academic achievement even after controlling the effects of prior achievement (Byrne, 1996; Marsh and Craven, 2006; Valentine and DuBois, 2005; Valentine, DuBois, and Cooper, 2004). In this and other work (Marsh and Craven, 1997; Marsh and O'Mara, 2008) the authors argue that academic self-concept and achievement are mutually reinforcing, each leading to gains in the other. The existence of this virtuous cycle may offer policy 
makers a relatively easy way to improve academic outcomes if by targeting interventions to improve academic self-concept that virtuous cycle is set in motion. However, this also means there is a potential for reverse causality, which we discuss further in the methods section.

More recently, Strand (2014) uses the Longitudinal Study of Young People in England (LSYPE) to examine a range of factors that might be able to account for gender, ethnic, and SES gaps in academic achievement and academic progress between the ages of 11-16. He finds that students' academic self-concept is positively related to progression and achievement and is one of the most important factors in accounting for observed gaps. Chowdry et al. (2011), like Strand, make use of the LSYPE to identify explanations for the socio-economic attainment gap. They find that a young person's belief in their academic ability at age 14 is positively and strongly associated with attainment at age 16. They then look at the relationship between income and academic self-concept and find that the relationship between academic self-concept and income reverses once prior attainment is controlled for, meaning that poorer young people are actually more likely to think they are doing well at school than richer young people, holding prior attainment constant. Where Chowdry et al. examine selfconcept by income, we focus on the combinations of high/low prior attainment and high/low selfconcept to examine whether over confidence, under confidence and accurately assessing academic self-concept may influence subsequent attainment.

The attainment measure we explore in this paper is GCSEs (General Certificate of Secondary Education) which are exams taken in England, Wales and Northern Ireland at the age of 16. Performance in these exams is pivotal for pupils in determining future academic and career pathways. Prior to 2015 , and for the cohort of children examined in this paper, pupils who performed badly at GCSEs were likely to leave education or remain studying level 2 qualifications post age 16 . Around half progress no further up the educational ladder (Hupkau et al., 2016). We say more about the GCSE measures used in the Data and Methods section. 
Academics and policy makers have long been keen to explore the correlates of achievement at GCSE level and identify the drivers of inequalities and achievement gaps. There is concern that achievement at 16 is strongly determined by the socio-economic background of pupils with all the implications this has for inequality of opportunity and lack of social mobility. This paper contributes to the existing literature around GCSE attainment by examining the role academic self-concept plays in understanding differences in GCSE results.

Drawing on both the GCSE achievement literature and the self-concept literature we build models which allow us to examine the relationship between academic self-concept (subsequently referred to as ASC) and GCSE attainment. Using data from the Next Steps Survey we address a number of research questions: What are the correlates of ASC? To what extent does ASC influence GCSE scores? And how does prior attainment and ASC interact in relation to GCSE scores? The data are described in the following section before descriptive - and then regression analyses are carried out and discussed. A summary section draws the paper to a close with a discussion of the results and the implications they may have.

\section{Data and Methods}

We use Next Steps (formerly LSYPE) which follows a cohort of children born in 1989/1990, resulting in seven waves of data. This cohort of young people can be linked with the National Pupil Database (NPD) which provides a census of children attending state schools in England.

Next Steps began in 2004 when the sample members were aged between 13 and 14 . Respondents were selected to be representative of young people in England using a stratified random sample, with disproportionate sampling for deprived schools. Schools were the primary sampling units, then children within schools. The two-stage sampling design presents a possible clustering effect due to between-school differences; therefore, all models are adjusted for school clustering and use appropriate weighting. 
Following the approach taken by Strand (2011), we create a composite measure of ASC using information collected at age $14^{1}$ using seven variables including the young person's report on whether they get good marks for their work; how good they think they are at school work; how good their teachers think they are at school work; and how good they think they are at: English, maths, science and ICT. ${ }^{2}$ Using a Principal Component Analysis (PCA) we reduce these responses into a component which has underlying similarities. The results from the data rotation identified one composite factor with an Eigenvalue of one or more (2.85) which explained 41 percent of the variance. The PCA-reduced variable is then used in the analysis after it is grouped into quintiles, where a low principal component score denotes low ASC and a high score denotes high self-concept.

Our main outcome of interest is GCSE results. The GCSE is a 2-year course examined toward the end of compulsory schooling when pupils are aged 16 . The grade scale runs from $A^{*}-G$, with Grade U (unclassified) signifying formal failure. Students, schools, employers, and the government place particular emphasis on a "good pass" of Grade C or above. The selected measure for capturing GCSE results is a binary measure of whether the young person achieved five GCSEs grade $A^{*}-C$, including English and Mathematics. This measure is particularly useful because it has significance for educational progression including studying for Advanced (A) level and, therefore, is linked to status attainment. As well as the binary measure of achieving five good GCSEs, a linear measure for GCSE scores is used as a robustness check. The linear measure is created by taking Grade $G$, the lowest grade achieved, to be 16 points. Each grade improvement thereafter, for example, from $G$ to $F, C$ to $B$, or $A$

\footnotetext{
${ }^{1}$ It is important that our measure of ASC is recorded at an earlier time period than our GCSE outcome scores (collected 2 years later) to reduce the possibility of reverse causality mentioned previously.

2Like Strand (2011) our measure includes what students think teachers think of them because a person's selfperception is likely to be formed through experience and interactions with one's environment (Shavelson et al., 1976) therefore related not only to personal attributes but also influenced by evaluations, or perceptions of evaluations of others (Marsh and O'Mara, 2008). The items are: "how much do you agree or disagree that I get good marks for my work" (Strongly agree; agree; disagree; disagree strongly; don't know); "And still thinking about some subjects at school, how good would you say you are at Maths/English/ Science/ ICT" (Very good; Fairly good; Not very good; No good at all); "How do you think your teachers would describe your school work?" (Very good; above average; average; below average; Not at all good; Don't know).
} 
to $A^{*}$, is equivalent to an additional six points. The linear measures are capped at 8 GCSEs and may include any points acquired through resits.

We make use of the first four waves to capture the main independent variables, which are: social class, ${ }^{3}$ parental education, equivalised permanent income, ${ }^{4}$ housing tenure, ethnicity, gender, special educational needs (SEN), Key Stage 2 (KS2) scores and school type attended. Some independent variables suffer from item non-response. In order to avoid dropping cases with missing or unknown information on background variables we take the first available response mentioned for parental class, parental education and household tenure over the first four waves. The main advantages of this approach are avoiding the loss of statistical power due to reduced $\mathrm{N}$ and minimising potential bias. We restrict the sample to only those students who respond to all seven of the measures of ASC (outlined above); students who we have GCSE results for; and students who we have a measure of prior attainment at age 11 (Key Stage 2 score $^{5}$ ). The exclusions result in an analytical sample of $10,144^{6}$.

Our modelling strategy is to use logistic regression multivariate models for our binary outcome (achieving $5 \mathrm{~A}^{*}$-C GCSEs) and convert the results to predicted probabilities to enable comparisons across models. When we use the linear GCSE score we use Ordinary Least Squares (OLS) regressions. When we compare ASC to measured achievement we do so by modelling typologies which have four categories, with no particular order, to them and therefore use

\footnotetext{
${ }^{3}$ Social class is measured using the National Statistics Socio Economic Classification (NS-SEC) which uses occupational types to capture dimensions of social class (Rose and Pevalin, 2001). We make use of the threecategory NS-SEC, which consists of: Higher Managerial, administrative and professional occupations; Intermediate occupations; Routine and manual occupations.

${ }^{4}$ We take an average of the household income over the first four waves and divide by the square root of household size to provide a measure of equivalised permanent income. This has been shown to have a greater association with young people's educational outcomes than transitory income (Jenkins and Schluter, 2002). ${ }^{5}$ Key Stage Two scores are derived from a Standard Assessment Test taken at age 11. Students were tested on the core curriculum of English, Maths, Science, History, Geography, IT, Design Technology, Art and Design, Music, Physical Education and Religious Education. The mean KS2 score is 27.2 with a standard deviation of 3.9, a minimum of 15 and a maximum of 36.

${ }^{6}$ We have GCSE results for 10,923, Key Stage Two results for 11,357, and ASC measures for 12,181. When we take a completed case study approach for all these three main variables of interest it results in an analytical sample of 10,144 .
} 
multinomial logistic regression. We acknowledge that our modelling strategy may be vulnerable to omitted variable bias, since our independent variables of interest, such as parental socio-economic status ${ }^{7}$, are likely to be correlated with individual- and school-level factors affecting a student's ability and ASC, although we try to minimise this issue through use of the rich background data (including prior attainment measures) available in Next Steps. Nevertheless, we do not view our results as truly causal, but rather capturing conditional relationships between background and ASC and self-concept and GCSE attainment. In addition, we account for the fact that observations are not truly independent from others attending the same school by calculating cluster-robust standard errors at school-level to conduct appropriate statistical inference. ${ }^{8}$

\section{Results}

The characteristics of pupils by their ASC, measured in quintiles, from the top 20 percent of the distribution (Q5) to the bottom 20 percent (Q1) are shown in Table 1. Students with high levels of ASC have higher key stage two results, higher linear GCSE scores and a higher proportion of them achieve five A*-C GCSEs. A greater proportion of those in the top 20 percent of ASC have a parent from a higher managerial job; have a parent educated to degree level or higher; live in households with higher equivalised family income; and attend an Independent school. A smaller proportion of those in the higher quintiles of ASC are women or have Special Education Needs (SEN) ${ }^{9}$.

\section{[TABLE 1 HERE]}

To examine more fully, whether ASC varies systematically across certain groups, as the descriptive statistics indicate it may well do, we run multivariate OLS regression models predicting ASC. The results, shown in Table 2, model family level variables, individual characteristics, school type and

\footnotetext{
${ }^{7}$ We take this to mean an individual's social and economic position in relation to others, based on measure of education, occupation, equivalised household income and household tenure.

${ }^{8}$ The frequencies (and means) for the variables are reported in Table 1.

${ }^{9}$ This is diagnosed and known SEN taken from the National Pupil Database.
} 
prior achievement. The dependent variable in these models is a standardised measure of ASC with a mean of zero and a standard deviation of one so coefficients are interpreted as standard deviation differences in ASC per unit increase in any continuous independent variable or as the standard deviation difference in ASC between any categorical variable and the reference group.

[TABLE 2 HERE]

The results indicate that parental class is not significantly associated with a pupils' ASC, net of individual, school level and family background characteristics. However, the results demonstrate that students with less educated parents have significantly lower levels of ASC than those whose parents have a degree. Income during adolescence also significantly predicts ASC, where those from wealthier households have higher levels of ASC. Housing tenure is not significantly associated with ASC net of these other background variables.

With respect to individual characteristics we see that compared to white pupils, all black and minority ethnic groups have higher levels of ASC except those who are from a mixed ethnicity background whose ASC is not significantly different from white pupils. This finding is consistent with the literature on aspirations which shows that ethnic minority groups tend to have higher aspirations than the majority group (MacLeod, 2009; Wilson and Wilson 1992). This may reflect more pro-school attitudes amongst these groups than the white group. Alongside ethnic differences there are also gender differences, with girls reporting lower levels of ASC than boys. There are no significant differences found regarding Special Education Needs (SEN) or school type. Unsurprisingly, we see a positive association between prior attainment and ASC; as Key Stage 2 scores increase pupils are more likely to report having higher ASC.

\section{GCSE attainment}

Turning now to the relationship between ASC and GCSE attainment, we make use of the covariates used in Table 2 to account for observable family, school and individual characteristics that may be related to GCSE attainment. In this way, while controlling for other factors that may influence GCSE 
results, our models are examining the role ASC plays in GCSE attainment. The results are shown in Table 3 for the capped linear GCSE score and the predicted probabilities of achieving five A*-C GCSEs are shown in Table 4. These outcomes are distinct but complementary, the linear result is a more fine-grained measure of attainment, while the five $A^{*}$-C GCSEs is a government benchmark and therefore arguably has a more substantive meaning. In both cases, there is a positive and significant association between ASC and GCSE attainment. Those who report the highest level of ASC (the top 20\% (Q5)) achieve 41.1 more points in their GCSEs than those from the bottom 20 percent (Table 3, Model b). This is equivalent to one additional C grade at GCSE or achieving over six As instead of six Bs. The inclusion of ASC does not wipe out the attainment differences by social background, income, ethnicity, gender or SEN status, but does reduce the achievement gap across most measures. Ethnic differences narrow once ASC is added to the model, perhaps reflecting the fact that ASC is higher amongst the non-white groups and therefore accounts for more variation in their GCSE scores so that their achievement advantage seen in model a is reduced once ASC is added to the model. However, it remains the case that white British pupils are consistently the lowest achieving ethnic group, net of ASC and background controls, this finding is consistent with the work of Strand (2014). The gap between boys and girls, on the other hand, widens slightly once ASC is taken into account with girls having a greater lead over boys. This may reflect the fact that boys have higher ASC than girls, so it accounts for more variation in their GCSE scores than girls, thereby widening the already existing gap in achievement between boys and girls. These relationships are examined in terms of predicted probabilities in Table 4, which shows that controlling for other factors, the probability of achieving five $A^{*}$-C GCSEs is 18 percent greater for those who are in the top quintile of ASC compared to those in the bottom quintile.

[TABLE 3 HERE]

[TABLE 4 HERE]

The results so far indicate that, even after controlling for a range of other factors related to GCSE attainment, ASC is associated with a relatively large improvement in GCSE scores. On average, 
students with higher ASC attain better grades than students with otherwise identical characteristics and prior attainment, but with lower levels of ASC. Another way to look at this to take two groups of equally able students who vary in the level of their ASC, controlling for the same variables as we did previously, we can then examine differences in their GCSE outcomes. Because we are controlling for other characteristics any statistically significant difference can be attributed to the difference in ASC. In addition, we can do this for groups of pupils at different points in the achievement distribution to see whether ASC matters more at the top of the distribution than the bottom. To do this we construct a typology based on both a student's self-concept and their prior attainment in year 6 at age 10-11 (Key Stage 2), this follows a similar approach taken by Khattab, (2015) who identified a mismatch of aspiration, expectation and prior attainment. Here our focus is on the mismatch of ASC and actual ability as captured by Key Stage 2 scores. Our typology identifies four groups of students - those who have both high ASC and high prior attainment (their ASC is well founded); high ASC, but low prior attainment (these students overestimate their ability); low ASC but high prior attainment (these students underestimate their academic ability); and finally, students with low ASC and low prior attainment (their ASC is in line with their ability).

The first stage of creating this typology is to identify high achievers and low achievers, we do this taking students' prior attainment (Key Stage 2 scores) and taking the top 40 percent and the bottom 40 percent. We then identify the ASC rating, grouping students with higher self-concept (top 40\%) and lower self-concept (bottom 40\%). This creates four new categories outlined below and a new analytical sample of 7,223:

The 'disconnected: these young people, who account for 34.9 percent of the sample are in the bottom two quintiles for prior attainment and are also in the bottom two quintiles of the ASC distribution.

The 'deluded': these young people have low prior attainment (the bottom two quintiles of key stage 2) but report having high ASC (in the top two quintiles of ASC). They are operating under an illusion that they are doing well at school. The deluded account for 14.9 percent of the sample. 
The 'uncertain': these young people were high achievers at age 11 - in the top 40 percent, but are located in the bottom 40 percent of the ASC distribution. They make up 14.6 percent of the sample.

The 'self-assured': these young people score in the top 40 percent of the Key Stage 2 results and also lie in the top 40 percent in the ASC distribution. They account for 35.6 percent of this sample.

\section{[TABLE 5 HERE]}

In order to identify the antecedents of these categories we first run a multinomial logit with the family, school and individual characteristics as independent variables. The results (in Table 5) show the significant predictors of belonging to the disconnected group, that is those with low levels of prior attainment and low ASC are coming from lower educated families (for example compared to those with highly educated parents, those whose parents have a Level 1 and below qualifications have a $22 \%$ chance of belonging to this group) and lower social class backgrounds (those from a routine background have an $8 \%$ higher probability, and those with an intermediate background have a $6 \%$ higher probability, of being disconnected than those from a higher managerial background). Family income also matters, where income increases by $£ 10,000$ there is a 4 percent lower chance of being disconnected. There is also evidence of a significant ethnic difference, where compared to white students Indians and Black Africans have a 10 percent lower chance of being disconnected, Pakistanis a 6 percent lower chance and Bangladeshis a 9 percent lower chance of being disconnected. While Black Caribbean young people have a 10 percent greater chance of being disconnected. There is no significant gender difference in belonging to this category.

For those who we are describing as deluded, that is those who have lower levels of prior attainment but who have high levels of ASC, we see similar patterns with respect to parental education, SEN, housing and income, although the magnitude of the association is larger than for the disconnected group. We see more of a mismatch between prior attainment and ASC among Indian, 
Pakistani, Bangladeshi and Black African students compared to white young people, recording an 11 percent, 20 percent, 5 percent, 17 percent and 7 percent (respectively) greater chance of being deluded. There is no evidence of a significant gender difference in belonging to this group, however those who study at an independent school see an 8 percent lower chance of being deluded than those who attend state and grammar schools.

Turning now to the uncertain category, those who have high levels of prior attainment but who have low levels of ASC, we see that compared to white pupils, those with any ethnic minority status have lower probabilities of being in the uncertain group. Girls are slightly more likely to be uncertain than boys and SEN reduces the probability of belonging to this group. There is no association for the independent school variable in this category.

For the self-assured category, who have both high ASC and high prior attainment, there is a negative class gradient where those from lower class categories have a lower chance of being selfassured. This is also reflected in the parental education gradient which is monotonically and negatively associated with being self-assured. Household resources such as income and housing tenure are also significant predictors of being self-assured. Young people living in households with higher incomes have a greater probability of belonging to this group and those living in rented accommodation have a lower probability of being self-assured compared to those in owner occupied housing. In terms of ethnic differences, we see that Indian and Bangladeshi young people have a higher change of being self-assured compared to white people ( $6 \%$ and $14 \%$ respectively). Having SEN status decreases the chance of being self-assured by 28 percent and studying in an independent school increases the chance of being self-assured by 14 percent. Finally, girls have a 3 percent lower chance of being self-assured than boys.

\section{[TABLE 6 HERE]}

Taking family, individual and school characteristics into account, we can see that these typologies are important predictors of GCSE attainment (Table 6). Model a shows the predicted probabilities of 
attaining $5 \mathrm{~A}^{*}$-C GCSEs between the self-assured (high attainers and high self-believers); the uncertain (high attainers with low ASC); the deluded (low achievers with high self-concept) and disconnected (low achievers with low ASC). The results show that compared to the self-assured those who are disconnected have a 65 percent reduction in the probability of achieving five $A^{*}$-C GCSEs, while those who are deluded see a 50 percent reduction in probability compared to the self-assured. Thus, having low prior attainment but having high ASC increases the probability of doing well at GCSEs by around 15 percentage points. Being uncertain, having high achievement but low ASC, reduces the predicted probability of achieving the government benchmark at GCSE by 19 percentage points compared to the self-assured.

When we look at the relationship between these typologies and a linear measure of GCSE attainment (Model b) the results now indicate the difference between the groups in terms of GCSE point scores. The high achieving young people with high ASC (the self-assured) score, on average, 389 points. Compared to those, similar high attainers who have low ASC (the uncertain) attract a coefficient of -43 , meaning the average GCSE point score for this group is 345 . To put it another way, the difference that confidence makes at this top end of ability equates to achieving seven As rather than seven Bs. Whilst for the lowest achievers, those with high ASC achieve on average 284 points compared to those with low ASC who only achieve an average of 263 points. So, at the bottom end of the ability distribution the difference between having high ASC and not equates to a difference of 21 GCSE points, so for example those with higher ASC at this bottom end (the deluded) might achieve almost four As compared to the almost four Bs achieved by similarly low ability students who have low ASC. So again, the penalty of low ASC amongst the highest achieving children appears to be greater than amongst the low achievers.

\section{Robustness check}

As a sensitivity test we also run models with an interaction term between ASC and prior attainment on GCSE results for the original sample. The results, on the whole, confirm the typology analysis: that 
the relationship between ASC and GCSE attainment varies by prior ability over and above the main effects. For the binary outcome (the probability of achieving five A*-C GCSEs (Table 7, column 1)) the interaction effect yields a positive and significant result indicating that ASC is more important at the top end of the ability distribution than at the bottom end. For the linear GCSE score (column 2) the interaction effect does not achieve statistical significance, which may not be surprising given the more fine-grained nature of the measure.

[TABLE 7 HERE]

\section{Discussion and Conclusion}

This paper uses data from Next Steps to examine correlates of ASC, and to explore the extent to which ASC influences GCSE performance. The results show that most pupils have high ASC, but this varies significantly by the characteristics of the children, their families and the school they attend. Findings suggest that prior attainment is an important predictor of ASC and also accounts for socio-economic differences in self-concept, reducing previously significant differences in income and housing tenure to statistical insignificance. However, over and above prior attainment, ASC varies by parental education, ethnic background and gender.

In terms of GCSE attainment, the results show a positive and significant association between ASC and both GCSE points and the likelihood of attaining 5 grade $A^{*}$ to C GCSEs. On average, pupils with ASC in the top 20 percent of the distribution achieve 41.1 more points in their GCSEs than the 20 percent of pupils with the lowest levels of ASC. When the relationships are examined in terms of predicted probabilities the probability of achieving five $A^{*}$-C GCSEs is 18 percent greater for those who are in the top quintile of ASC compared to those in the bottom quintile.

When we examine similar groups of pupils at the top and bottom of the prior ability distribution (with our 4 scale typology of self-assured, uncertain, deluded and disconnected) the 
results look the same. They show that both high and low attainers have higher probabilities of achieving five $A^{*}-C$ GCSEs and higher GCSE point scores on average if they have higher ASC than similarly able students who have lower self-concept. In addition, the results show the penalty for lack of ASC at the top end is greater than the advantage of high self-concept at the bottom end of the ability distribution. In terms of GCSE point scores, the gap at the top of the ability distribution between those with high and low ASC is 43 points compared to the 21 point gap found between those with high and low ASC amongst pupils in the lowest 20 percent of the ability distribution. These results are confirmed when we run interaction models between prior ability and ASC on the probability of achieving five $A^{*}-C$ GCSEs, but we should exercise a degree of caution as the interaction using the linear measure of GCSE scores is not statistically significant.

The implications of these findings would seem to suggest that if policy makers and teachers were to focus on increasing the ASC of pupils, they might also increase their performance at GCSEs. Teachers and parents could be encouraged to build this aspect into their educational interactions with children, and programmes to instil confidence in pupils could be easy incorporated into their learning. In this paper we are able to identify certain pupils, who, all other things being equal, have less belief in their academic ability than others, who could be the target of such interventions: those with less educated parents; white pupils; girls; and pupils with lower achievement at Key Stage 2. Targeting these pupils would raise their ASC relative to others and subsequently, their GCSE scores. However, in reality things are more complicated than this as achievement at age eleven, plays a role in later self-concept so any intervention would need to occur at an early age and, in all likelihood, would need to be an ongoing process to counter differences in performance throughout the school system up to age 16 . This recommendation is in line with the work of Marsh and Craven $(1997,2006)$ and Marsh and O'Mara (2008) who argue that there is a reciprocal relationship between ASC and academic achievement. 
Our analysis found an association with ASC and attainment even after taking into account differences in family background, individual characteristics and school type but we are unable to elaborate on what it is about ASC that produces differences in GCSE scores. For example, it may be that pupils with higher levels of ASC are able to enter GCSE exams in a more relaxed manner which produces an enhanced performance relative to their similarly able, but less confident, peers. It may also be that their increased ASC already means they have their educational pathway through A-levels and University mapped out and are therefore more invested in making it happen through more time spent on revision and homework than their less confident peers who are more tentative about their academic future. This would perhaps suggest there is an interplay between ASC and other psychological constructs such as locus of control (the extent to which people feel that they have control over the outcomes of events in their lives), efficacy (the ability to produce a desired outcome), self-regulation, motivation and higher aspirations. Although not explored in this paper, unpicking such mechanisms in future research would be an important part of the picture for policy makers and researchers alike. 


\section{References}

Baumeister R., J. Campbell, J. Krueger and K. Vohs (2003) Does high self-esteem cause better performance, interpersonal success, happiness or healthier lifestyles?, Psychological Science in the Public Interest, 4, 1-44.

Branden, N. (1994) Six pillars of self-esteem. New York: Bantam.

Byrne, B. (1996) Academic self-concept: Its structure, measurement, and relation to academic achievement. In B. Bracken (Ed.), Handbook of self-concept (pp. 287-316). New York: John Wiley.

Chowdry, H., Crawford, C. and Goodman, A. (2011) 'The role of attitudes and behaviours in explaining socio-economic differences in attainment at age 16 '. Longitudinal and Life Course Studies, $2(1), 59-76$

Correll S. (2001) Gender and the Career Choice Process: The Role of Biased Self-Assessments. American journal of Sociology. 106(6):1691-730.

Craven, R., Marsh, H. and Burnett, P. (2003) Cracking the self-concept enhancement conundrum: A call and blueprint for the next generation of self-concept enhancement research. In Marsh, Craven, and McInerney (Eds.), International advances in self research (Vol. 1, pp. 67-90). Greenwich, CT: Information Age.

Dunning D., C. Heath and Suls, J. (2004) Flawed Self-Assessment, Psychological Science in the Public Interest. 5: 69-106.

Falchikov N. and Boud, D. (1989) Student Self-Assessment in Higher Education: a Meta Analysis, Review of Educational Research, 59, 395-430.

Gorard, S. (2012) Querying the causal role of attitudes in educational attainment, ISRN Education, Vol. 2012, Article ID 501589.

Gorard, S., See, B. and Davies, P. (2011) Do attitudes and aspirations matter in education? A review of the research evidence. Saarbrucken: Lambert Academic Publishing.

Hupkau C., McNally, S., Ruiz-Valenzuela, J and Ventura, G. (2016) Post-Compulsory Education in England: Choices and Implications, CVER Discussion Paper 001.

Joffe, L. and Foxman, D., 1988. Attitudes and gender differences. Slough, NFER-Nelson.

Khattab N. (2015) Students' aspirations, expectations and school achievement: what really matters? British Educational Research Journal. 41(5):731-48.

MacLeod, J. (2009). Ain't No Makin' It: Aspirations and Attainment in a Low-Income Neighborhood, Taylor and Francis, New York.

Marsh, H. (1989) Sex-Differences in the Development of Verbal and Mathematics Constructs - the High-School and Beyond Study, American Educational Research Journal. 26 (2): 191-225.

Marsh, H. and Craven, R. (1997) Academic self-concept: Beyond the dustbowl. In G. Phye (Ed.), Handbook of classroom assessment: Learning, achievement, and adjustment (pp. 131-198). Orlando, 


\section{FL: Academic Press.}

Marsh, H. and Craven, R. (2006) Reciprocal effects of self-concept and performance from a multidimensional perspective: Beyond seductive pleasure and unidimensional perspectives. Perspectives on Psychological Science, 1, 133-163.

Marsh, H. and Hau, K. (2003) Big-fish-little-pond effect on academic self-concept - A cross-cultural (26country) test of the negative effects of academically selective schools, American Psychologist. 58: 3646.

Marsh, H. and O'Mara, A. (2008) Reciprocal effects between academic self-concept, self-esteem, achievement, and attainment over seven adolescent years: unidimensional and multidimensional perspectives of self-concept, Personality and Social Psychology Bulletin, 34(4): 542-552.

Marsh, H. and Yeung, A. (1998) Longitudinal structural equation models of academic self-concept and achievement: Gender differences in the development of math and English constructs, American Educational Research Journal. 35, (4): 705-38.

Rose, D and Pevalin, D.J. (2001). The National Statistics Socio-economic Classification: Unifying Official and Sociological Approaches to the Conceptualisation and Measurement of Social Class. ISER.

See, B and Gorard, S. (2015) The role of parents in young people's education - a critical review of the causal evidence, Oxford Review of Education, 41:3, 346-366.

Shavelson, R., Hubner, J. and Stanton, G. (1976) Validation of construct interpretations. Review of Educational Research, 46: 407-441.

Strand, S. (2011) The Limits of Social Class in Explaining Ethnic Gaps in Educational Attainment. British Educational Research Journal 37 (2): 197-229.

Strand, S. (2014) Ethnicity, gender, social class and achievement gaps at age 16: Intersectionality and 'Getting it' for the white working class. Research Papers in Education, 29(2): 131-171.

Sullivan, A. (2006) Academic self-concept, Gender and Single-sex Schooling in the 1970 Cohort, CLS Working Paper, London: Centre for Longitudinal Studies 2006, (2).

Sullivan A. (2009) Academic self-concept, gender and single-sex schooling. British educational research journal. 35(2):259-88.

Valentine, J. and DuBois, D. (2005) Effects of self-beliefs on academic achievement and vice-versa: Separating the chicken from the egg. In H. Marsh, R. Craven and D. Mclnerney (Eds.), International advances in self research (Vol. 2, pp. 53-78). Greenwich, CT: Information Age.

Valentine, J., DuBois, D. and Cooper, H. (2004) The relations between self-beliefs and academic achievement: A systematic review. Educational Psychologist, 39: 111-133.

Wilson, Patricia M. and Jeffrey R. Wilson. 1992. "Environmental Influences on Adolescent Educational Aspirations: A Logistic Transform Model." Youth \& Society 24:52-70. 
Table 1.Descriptive Statistics

\begin{tabular}{|c|c|c|c|c|c|c|}
\hline Variables & $\begin{array}{l}\text { Academic } \\
\text { Self } \\
\text { Concept } \\
\text { Q1 }\end{array}$ & $\begin{array}{l}\text { Academic } \\
\text { Self } \\
\text { Concept } \\
\text { Q2 }\end{array}$ & $\begin{array}{l}\text { Academic } \\
\text { Self } \\
\text { Concept } \\
\text { Q3 }\end{array}$ & $\begin{array}{l}\text { Academic } \\
\text { Self } \\
\text { Concept } \\
\text { Q4 }\end{array}$ & $\begin{array}{l}\text { Academic } \\
\text { Self } \\
\text { Concept } \\
\text { Q5 }\end{array}$ & Total \\
\hline \multicolumn{7}{|l|}{ YP Education } \\
\hline Total & $20.00 \%$ & $20.00 \%$ & $20.00 \%$ & $20.00 \%$ & $20.00 \%$ & $100 \%$ \\
\hline Key Stage 2 results (mean) & 25.4 & 26.7 & 28 & 28.375 & 29.43 & 27.48 \\
\hline Linear GCSE results (mean) & 250.78 & 290.74 & 324.41 & 336.58 & 362.59 & 310.11 \\
\hline Five GCSEs $A^{*}-C$ & $12.69 \%$ & $17.16 \%$ & $23.13 \%$ & $23.08 \%$ & $23.94 \%$ & $100 \%$ \\
\hline \multicolumn{7}{|l|}{ Social class background } \\
\hline Higher Managerial & $15.29 \%$ & $16.87 \%$ & $22.90 \%$ & $21.80 \%$ & $23.13 \%$ & $100 \%$ \\
\hline Intermediate & $22.31 \%$ & $22.31 \%$ & $20.20 \%$ & $17.90 \%$ & $17.29 \%$ & $100 \%$ \\
\hline Routine & $26.25 \%$ & $20.63 \%$ & $19.29 \%$ & $18.23 \%$ & $15.59 \%$ & $100 \%$ \\
\hline \multicolumn{7}{|l|}{ Highest parental qualification } \\
\hline Degree or Higher & $13.24 \%$ & $16.05 \%$ & $22.36 \%$ & $21.17 \%$ & $27.18 \%$ & $100 \%$ \\
\hline Other HE qualification & $19.86 \%$ & $20.57 \%$ & $22.45 \%$ & $18.58 \%$ & $18.54 \%$ & $100 \%$ \\
\hline A Level & $20.13 \%$ & $20.13 \%$ & $21.66 \%$ & $21.01 \%$ & $17.07 \%$ & $100 \%$ \\
\hline GCSE A-C & $27.45 \%$ & $22.01 \%$ & $18.91 \%$ & $18.06 \%$ & $13.57 \%$ & $100 \%$ \\
\hline GCSE D-G and below & $26.76 \%$ & $20.68 \%$ & $18.85 \%$ & $17.49 \%$ & $16.23 \%$ & $100 \%$ \\
\hline \multicolumn{7}{|l|}{ Income } \\
\hline $\begin{array}{l}\text { Equivalised household income } \\
(£ 10,000) \text { Mean }\end{array}$ & 1.34 & 1.44 & 1.62 & 1.62 & 1.74 & 1.55 \\
\hline \multicolumn{7}{|l|}{ Household Tenure } \\
\hline$\overline{\text { Owns Property Outright/Mortgage }}$ & $20.48 \%$ & $19.70 \%$ & $20.87 \%$ & $19.71 \%$ & $19.25 \%$ & $100 \%$ \\
\hline Rent/Other & $27.99 \%$ & $21.41 \%$ & $19.18 \%$ & $17.17 \%$ & $14.25 \%$ & $100 \%$ \\
\hline \multicolumn{7}{|l|}{ Ethnicity } \\
\hline White & $23.66 \%$ & $20.36 \%$ & $20.43 \%$ & $18.53 \%$ & $17.02 \%$ & $100 \%$ \\
\hline Mixed & $19.37 \%$ & $19.80 \%$ & $18.27 \%$ & $22.14 \%$ & $20.43 \%$ & $100 \%$ \\
\hline Indian & $13.17 \%$ & $17.14 \%$ & $18.10 \%$ & $24.94 \%$ & $26.65 \%$ & $100 \%$ \\
\hline Pakistani & $12.20 \%$ & $17.88 \%$ & $22.00 \%$ & $23.96 \%$ & $23.95 \%$ & $100 \%$ \\
\hline Bangladeshi & $15.09 \%$ & $17.77 \%$ & $24.47 \%$ & $18.41 \%$ & $24.26 \%$ & $100 \%$ \\
\hline Black Caribbean & $19.56 \%$ & $23.22 \%$ & $21.76 \%$ & $20.46 \%$ & $15.01 \%$ & $100 \%$ \\
\hline Black African & $10.57 \%$ & $17.27 \%$ & $18.01 \%$ & $26.25 \%$ & $27.90 \%$ & $100 \%$ \\
\hline Other & $13.04 \%$ & $19.14 \%$ & $21.03 \%$ & $19.78 \%$ & $27.01 \%$ & $100 \%$ \\
\hline \multicolumn{7}{|l|}{ Gender } \\
\hline Male & $20.55 \%$ & $19.71 \%$ & $21.58 \%$ & $19.66 \%$ & $18.51 \%$ & $100 \%$ \\
\hline Female & $24.66 \%$ & $20.65 \%$ & $19.19 \%$ & $18.33 \%$ & $17.17 \%$ & $100 \%$ \\
\hline \multicolumn{7}{|l|}{ Special Education Needs } \\
\hline$\overline{\text { No Special Education Needs }}$ & $20.93 \%$ & $20.26 \%$ & $20.92 \%$ & $19.57 \%$ & $18.32 \%$ & $100 \%$ \\
\hline Special Education Needs & $42.82 \%$ & $19.09 \%$ & $14.00 \%$ & $12.03 \%$ & $12.07 \%$ & $100 \%$ \\
\hline \multicolumn{7}{|l|}{ School type } \\
\hline$\overline{\text { Not Independent school }}$ & $22.75 \%$ & $20.42 \%$ & $20.32 \%$ & $18.87 \%$ & $17.64 \%$ & $100 \%$ \\
\hline \multirow[t]{2}{*}{ Independent school } & $17.52 \%$ & $12.54 \%$ & $22.79 \%$ & $22.88 \%$ & $24.27 \%$ & $100 \%$ \\
\hline & & & & & & $N=10,144$ \\
\hline
\end{tabular}


Table 2 OLS Regression Predicting Academic Self Concept (z-scores)

\begin{tabular}{|c|c|c|}
\hline & $\beta$ & SE \\
\hline \multicolumn{3}{|l|}{ Ref. Higher Managerial } \\
\hline Intermediate & -0.06 & $(0.03)$ \\
\hline Routine & -0.00 & $(0.03)$ \\
\hline \multicolumn{3}{|l|}{ Ref. Degree or equivalent } \\
\hline Other HE qualification & $-0.10 * *$ & $(0.04)$ \\
\hline A Level & $-0.12 * *$ & $(0.04)$ \\
\hline GCSE A-C & $-0.16 * * *$ & $(0.03)$ \\
\hline Level 1 and below & $-0.10 *$ & $(0.04)$ \\
\hline Equivalised household income $(£ 10,000)$ & $0.03 *$ & $(0.01)$ \\
\hline \multicolumn{3}{|l|}{ Ref. Owns home or Mortgage } \\
\hline Rent/Other & 0.04 & $(0.03)$ \\
\hline \multicolumn{3}{|l|}{ Ref. White } \\
\hline Mixed & 0.10 & $(0.05)$ \\
\hline Indian & $0.41 * * *$ & $(0.05)$ \\
\hline Pakistani & $0.52 * * *$ & $(0.05)$ \\
\hline Bangladeshi & $0.39 * * *$ & $(0.06)$ \\
\hline Black Caribbean & $0.18^{* *}$ & $(0.06)$ \\
\hline Black African & $0.51 * * *$ & $(0.07)$ \\
\hline Other & $0.36 * * *$ & $(0.07)$ \\
\hline \multicolumn{3}{|l|}{ Ref. Boys } \\
\hline Girls & $-0.12 * * *$ & $(0.02)$ \\
\hline \multicolumn{3}{|l|}{ Ref. No Special Education Needs (SEN) } \\
\hline SEN & -0.00 & $(0.07)$ \\
\hline \multicolumn{3}{|l|}{ School type } \\
\hline Independent school & -0.04 & $(0.07)$ \\
\hline Attainment (Key stage 2 results) & $0.09 * * *$ & $(0.00)$ \\
\hline Constant & $-2.52 * * *$ & $(0.15)$ \\
\hline Observations & \multicolumn{2}{|c|}{10,144} \\
\hline R-squared & \multicolumn{2}{|c|}{0.16} \\
\hline
\end{tabular}




\begin{tabular}{|c|c|c|c|c|}
\hline & \multicolumn{2}{|c|}{ Model a } & \multicolumn{2}{|c|}{ Model b } \\
\hline & $\beta$ & SE & $\beta$ & SE \\
\hline \multicolumn{5}{|l|}{ Ref. Academic Self Concept (Q1) } \\
\hline Q2 & & & $15.92 * * *$ & $(2.34)$ \\
\hline Q3 & & & $27.75^{* * *}$ & $(2.34)$ \\
\hline Q4 & & & $33.62 * * *$ & $(2.57)$ \\
\hline Q5 & & & $41.12 * * *$ & $(2.75)$ \\
\hline \multicolumn{5}{|l|}{ Ref. Higher Managerial } \\
\hline Intermediate & -1.67 & $(1.76)$ & -0.55 & $(1.73)$ \\
\hline Routine & $-9.13 * * *$ & (1.99) & $-8.74 * * *$ & (1.96) \\
\hline \multicolumn{5}{|l|}{ Ref. Degree or equivalent } \\
\hline Other HE qualification & $-7.51 * * *$ & $(2.12)$ & $-6.23 * *$ & $(2.07)$ \\
\hline A Level & $-10.05^{* * *}$ & $(2.26)$ & $-8.72 * * *$ & (2.18) \\
\hline GCSE A-C & $-17.87 * * *$ & (2.10) & $-15.72 * * *$ & (2.07) \\
\hline Level 1 and below & $-27.26 * * *$ & $(2.91)$ & $-26.14 * * *$ & $(2.88)$ \\
\hline Equivalised household income $(£ 10,000)$ & $5.44 * * *$ & $(0.83)$ & $5.14 * * *$ & $(0.79)$ \\
\hline \multicolumn{5}{|l|}{ Ref. Owns home or Mortgage } \\
\hline Rent/Other & $-23.19 * * *$ & $(2.12)$ & $-23.53 * * *$ & $(2.08)$ \\
\hline \multicolumn{5}{|l|}{ Ref. White } \\
\hline Mixed & 6.18 & $(4.27)$ & 4.65 & $(4.25)$ \\
\hline Indian & $36.58 * * *$ & $(2.87)$ & $31.12 * * *$ & $(2.84)$ \\
\hline Pakistani & $31.54 * * *$ & $(4.12)$ & $23.88^{* * *}$ & (3.96) \\
\hline Bangladeshi & $46.43 * * *$ & $(5.60)$ & $40.68 * * *$ & $(5.69)$ \\
\hline Black Caribbean & $8.75^{*}$ & (3.94) & 6.26 & $(3.84)$ \\
\hline Black African & $39.38 * * *$ & (5.58) & $31.95 * * *$ & $(5.38)$ \\
\hline Other & $46.03 * * *$ & (4.95) & $41.16 * * *$ & $(4.56)$ \\
\hline \multicolumn{5}{|l|}{ Ref. Boys } \\
\hline Girls & $19.27^{* * *}$ & $(1.57)$ & $21.24 * * *$ & $(1.56)$ \\
\hline \multicolumn{5}{|l|}{ Ref. No Special Education Needs (SEN) } \\
\hline SEN & $-30.99 * * *$ & $(4.03)$ & $-31.04 * * *$ & $(4.14)$ \\
\hline \multicolumn{5}{|l|}{ School type } \\
\hline Independent school & 14.07 & (9.19) & 14.68 & $(8.95)$ \\
\hline Attainment (Key stage 2 results) & $15.34 * * *$ & $(0.23)$ & $14.00 * * *$ & $(0.26)$ \\
\hline Constant & $-106.04 * * *$ & $(7.53)$ & $-93.53 * * *$ & (7.93) \\
\hline Observations & \multicolumn{2}{|c|}{10,144} & \multicolumn{2}{|c|}{10,144} \\
\hline R-squared & \multicolumn{2}{|c|}{0.60} & \multicolumn{2}{|c|}{0.62} \\
\hline
\end{tabular}

Standard errors in parentheses

*** $p<0.001, * * p<0.01, * p<0.05$ 
Model a Model b

PPSE $\quad$ PPSE

Ref. Academic Self Concept (Q1)

Q2

Q3

Q4

$0.06 * * *(0.01)$

$0.12 * * *(0.01)$

$0.15 * * *(0.01)$

Q5

$0.18^{* * *}(0.02)$

\section{Ref. Higher Managerial}

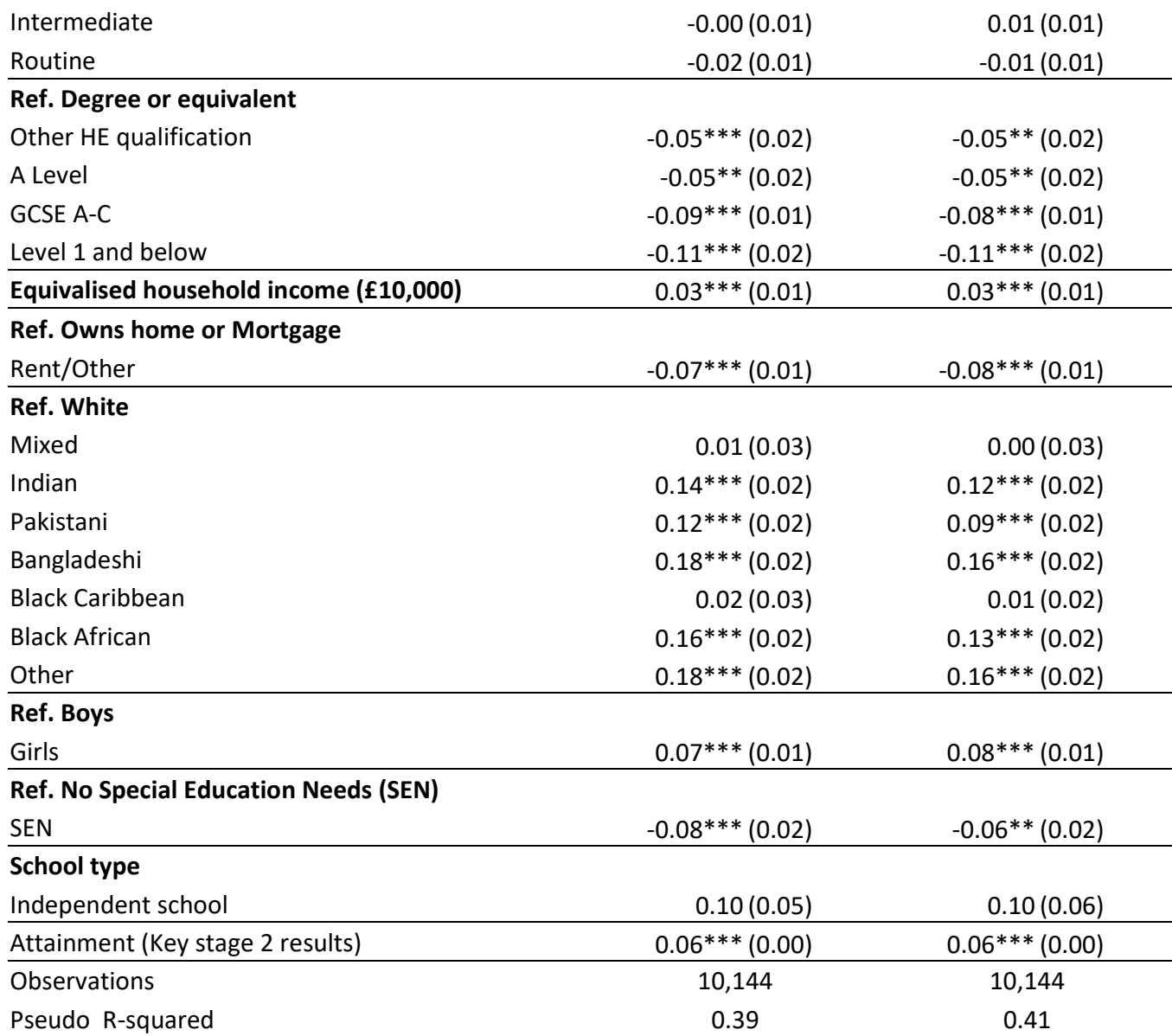

Standard errors in parentheses

*** $\mathrm{p}<0.001, * * \mathrm{p}<0.01, * \mathrm{p}<0.05$ 
Table 5 Multinomial Logistic Regression Predicting Typology Grouping

\begin{tabular}{|c|c|c|c|c|c|c|c|c|}
\hline & \multicolumn{2}{|c|}{ Disconnected } & \multicolumn{2}{|c|}{ Deluded } & \multicolumn{2}{|c|}{ Uncertain } & \multicolumn{2}{|c|}{ Self-Assured } \\
\hline & $P P$ & SE & $\mathrm{PP}$ & SE & PP & SE & PP & SE \\
\hline \multicolumn{9}{|l|}{ Ref. Higher Managerial } \\
\hline Intermediate & $0.06 * *$ & $(0.02)$ & -0.00 & $(0.01)$ & 0.02 & $(0.01)$ & $-0.08 * * *$ & $(0.02)$ \\
\hline Routine & $0.08 * * *$ & $(0.02)$ & 0.01 & $(0.01)$ & -0.01 & $(0.01)$ & $-0.08 * * *$ & $(0.02)$ \\
\hline \multicolumn{9}{|c|}{ Ref. Degree or equivalent } \\
\hline Other HE qualification & $0.12 * * *$ & $(0.02)$ & 0.01 & $(0.02)$ & -0.00 & $(0.02)$ & $-0.13 * * *$ & $(0.02)$ \\
\hline A Level & $0.08 * * *$ & $(0.02)$ & 0.02 & $(0.02)$ & 0.00 & $(0.02)$ & $-0.10 * * *$ & (0.03) \\
\hline GCSE A-C & $0.20 * * *$ & $(0.02)$ & $0.05^{* * *}$ & $(0.01)$ & $-0.04 * *$ & $(0.02)$ & $-0.21 * * *$ & $(0.02)$ \\
\hline Level 1 and below & $0.22 * * *$ & $(0.02)$ & $0.07 * * *$ & $(0.02)$ & $-0.07 * * *$ & $(0.02)$ & $-0.22 * * *$ & $(0.03)$ \\
\hline \multicolumn{9}{|l|}{ Equivalised household } \\
\hline \multicolumn{9}{|l|}{ Ref. Owns home or } \\
\hline Rent/Other & $0.06 * * *$ & $(0.02)$ & $0.03 * *$ & $(0.01)$ & -0.01 & $(0.01)$ & $-0.08 * * *$ & $(0.02)$ \\
\hline \multicolumn{9}{|l|}{ Ref. White } \\
\hline Mixed & -0.04 & $(0.03)$ & 0.02 & $(0.03)$ & -0.00 & $(0.03)$ & 0.03 & $(0.03)$ \\
\hline Indian & $-0.10 * * *$ & $(0.02)$ & $0.11 * * *$ & $(0.02)$ & $-0.08 * * *$ & $(0.02)$ & $0.06 *$ & $(0.02)$ \\
\hline Pakistani & $-0.06 *$ & $(0.03)$ & $0.20 * * *$ & $(0.02)$ & $-0.12 * * *$ & $(0.02)$ & -0.02 & (0.03) \\
\hline Bangladeshi & $-0.09 * *$ & $(0.03)$ & $0.05^{*}$ & $(0.02)$ & $-0.10 * * *$ & $(0.02)$ & $0.14^{* * *}$ & $(0.03)$ \\
\hline Black Caribbean & $0.10 *$ & $(0.05)$ & 0.04 & $(0.03)$ & $-0.08 * * *$ & $(0.02)$ & -0.05 & $(0.04)$ \\
\hline Black African & $-0.10 * *$ & $(0.03)$ & $0.17^{* * *}$ & $(0.04)$ & $-0.12 * * *$ & $(0.02)$ & 0.05 & $(0.04)$ \\
\hline Other & $-0.08^{*}$ & $(0.04)$ & $0.07 *$ & $(0.03)$ & -0.06 & $(0.03)$ & 0.07 & $(0.04)$ \\
\hline \multicolumn{9}{|l|}{ Ref. Boys } \\
\hline Girls & 0.00 & $(0.01)$ & -0.01 & $(0.01)$ & $0.04 * * *$ & $(0.01)$ & $-0.03 * *$ & $(0.01)$ \\
\hline \multicolumn{9}{|c|}{$\begin{array}{l}\text { Ref. No Special Education } \\
\text { Needs (SEN) }\end{array}$} \\
\hline SEN & $0.31 * * *$ & $(0.03)$ & $0.10^{* * *}$ & $(0.02)$ & $-0.12 * * *$ & $(0.01)$ & $-0.28 * * *$ & $(0.02)$ \\
\hline \multicolumn{9}{|l|}{ School type } \\
\hline Independent school & -0.12 & $(0.06)$ & $-0.08 * *$ & $(0.03)$ & 0.06 & $(0.06)$ & $0.14 *$ & $(0.07)$ \\
\hline
\end{tabular}


Table 6: Association between Academic Self Concept and Ability Typology predicting GCSE results

\begin{tabular}{lcccc}
\hline & \multicolumn{2}{c}{ Model a } & \multicolumn{2}{c}{ Model b } \\
& $5 A^{*}$-C GCSE & \multicolumn{2}{c}{$\begin{array}{c}\text { Capped Linear GCSE } \\
\text { score }\end{array}$} \\
& \multicolumn{3}{c}{ PP } & \multicolumn{2}{c}{$\beta$} & SE \\
\hline Ref: Self-assured & & & & \\
Disconnected & $-0.65^{* * *}$ & $(0.02)$ & $-126.26^{* * *}$ & $(2.74)$ \\
Deluded & $-0.50^{* * *}$ & $(0.02)$ & $-105.03^{* * *}$ & $(4.33)$ \\
Uncertain & $-0.19^{* * *}$ & $(0.02)$ & $-43.28^{* * *}$ & $(2.45)$ \\
\hline Constant & & & $389.30^{* * *}$ & $(3.95)$ \\
\hline Observations & 8,054 & \multicolumn{3}{c}{8,054} \\
Pseudo R2/R2 & 0.43 & \multicolumn{3}{c}{0.56} \\
\hline
\end{tabular}

Controlling for Social Class, parental education, income, household tenure, ethnicity, gender, SEN, and school type.

Standard errors in parentheses

$* * * \mathrm{p}<0.001,{ }^{* *} \mathrm{p}<0.01,{ }^{*} \mathrm{p}<0.05$

Table 7

\begin{tabular}{|c|c|c|c|c|}
\hline & \multicolumn{2}{|c|}{$\begin{array}{l}\text { Logistic Regression } \\
\text { Predicting Five A*-C } \\
\text { GCSE }\end{array}$} & \multicolumn{2}{|c|}{$\begin{array}{l}\text { OLS Regression Predicting } \\
\text { Linear Capped GCSE } \\
\text { points }\end{array}$} \\
\hline & Log Odds & $\mathrm{SE}$ & $\beta$ & SE \\
\hline Academic Self Concept & $0.88 * * *$ & $(0.07)$ & $33.26 * * *$ & (1.61) \\
\hline Key stage 2 & $0.14^{*}$ & $(0.06)$ & $8.84 * * *$ & $(2.09)$ \\
\hline ASC X KS2 & $0.08 * * *$ & $(0.02)$ & 0.49 & $(0.52)$ \\
\hline Constant & $-3.00 * * *$ & $(0.24)$ & $178.82 * * *$ & $(7.02)$ \\
\hline Adjusted $\mathrm{R}^{2}$ & \multicolumn{2}{|c|}{0.40} & \multicolumn{2}{|c|}{0.58} \\
\hline Observations & \multicolumn{2}{|c|}{10,144} & \multicolumn{2}{|c|}{10,144} \\
\hline
\end{tabular}

Controlling for class, parental education, household income, housing tenure, ethnicity, gender, SEN and school type

Standard errors in parentheses

*** $p<0.001, * * p<0.01, * p<0.05$ 